\title{
Collective rituals in team sports: Implications for team resilience and communal coping
}

\author{
Devin Bonk ${ }^{1, *}$, Chloé Leprince ${ }^{2}$, Katherine A. Tamminen ${ }^{3}$, and Julie Doron ${ }^{2,4}$ \\ ${ }^{1}$ Faculty of Kinesiology and Physical Education, University of Toronto, Toronto, Ontario, Canada \\ ${ }^{2}$ French Institute of Sport (INSEP), Research Department, Laboratory Sport, Expertise and Performance (EA 7370), Paris, \\ France \\ ${ }^{3}$ Faculty of Kinesiology and Physical Education, University of Toronto, Toronto, Ontario, Canada \\ ${ }^{4}$ University of Nantes, Laboratory "Movement, Interactions, Performance" (EA 4334), Faculty of Sport Sciences, \\ Nantes, France
}

Received 3 July 2018, Accepted 14 March 2019

\begin{abstract}
Many sports teams engage in collective rituals (e.g., the New Zealand All Blacks' haka). While the concept has been studied extensively in other fields (e.g., social psychology and cultural anthropology), literature on collective rituals specific to sport is limited. Leveraging theoretical positions and empirical findings from across the human and social sciences, the application of an existing definition of collective ritual in team sports is explored. Complementary research is suggestive of a potential link between collective rituals and two growing topics of interest in group dynamics, namely, team resilience and communal coping. Collective rituals can bolster team resilience by strengthening the group structure and increasing a team's social capital. They can also serve as communal coping strategies, helping to manage team stressors as they arise. However, at the extremes, collective rituals can become problematic. Over-reliance and abusive rites of passage (i.e., hazing) are considered. Potential applied implications and future research directions in sport psychology are then discussed.
\end{abstract}

Key words: team adaptation, team resilience, communal coping, group dynamics

\begin{abstract}
Résumé-Les rituels collectifs : implications pour la résilience et le coping des équipes sportives. De nombreuses équipes sportives s'engagent dans des rituels collectifs (e.g., le haka des All Blacks). Bien que ce concept ait été étudié plus largement dans d'autres champs que la psychologie du sport (e.g., la psychologie sociale, l'anthropologie culturelle), la littérature sur les rituels collectifs spécifiques au contexte sportif est limitée. L'application d'une définition existante des rituels collectifs dans les sports d'équipe est ici explorée au travers d'une recension des cadres théoriques et des résultats empiriques issus de la littérature en sciences humaines et sociales. Des liens potentiels sont également envisagés entre les rituels collectifs et deux cadres théoriques dont l'intérêt en psychologie du sport est grandissanti: la résilience d'équipe et la gestion collective du stress. Les rituels collectifs pourraient ainsi jouer un rôle dans la résilience d'équipe en renforçant la structure du groupe et son capital social. Ils pourraient également être utilisés par l'équipe comme stratégie collective de gestion du stress. En revanche, à l'opposé, les rituels collectifs peuvent dans certaines situations devenir problématiques, notamment la dépendance excessive et les rites de passage abusifs (i.e., le bizutage). Enfin, des implications pratiques et des perspectives de recherches prometteuses sont évoquées pour étudier les rituels collectifs dans le contexte sportif.
\end{abstract}

Mots clés : adaptation collective, résilience déquipe, coping collectif, dynamique de groupe

Collective rituals are highly prevalent in team sports. Perhaps the most notable example of this type of group behaviour is the pregame ritual of the New Zealand All Blacks. Before all international matches, they engage in a

\footnotetext{
*Corresponding author: devin. bonk@mail.utoronto.ca
}

traditional Māori Ka Mate haka war cry and dance, made up of intense synchronous shouts and movements. There may be more to the haka than opponent intimidation. It is an action sequence that, to the athletes performing it, is embedded with historical and cultural meaning (Jackson $\&$ Hokowhitu, 2002). Though other teams might have less 
structured and historically significant rituals (like a basic pre-game team cheer), their underlying mechanisms operate in a similar manner. Indeed, psychology researchers are beginning to identify the psychosocial benefits of collective rituals (Watson-Jones \& Legare, 2016; Whitehouse \& Lanman, 2014). Though only few studies have considered some group benefits of collective rituals in sport specifically (e.g., Murray, Joyner, Burke, Wilson, \& Zwald, 2005), the topic has been investigated extensively in other fields, such as social and cognitive psychology (e.g., Hobson, Gino, Norton, \& Inzlicht, 2017; Rossano, 2012), and evolutionary anthropology (e.g., Atkinson \& Whitehouse, 2011; Fischer, Callander, Reddish, \& Bulbia, 2013; Whitehouse \& Lanman, 2014). By leveraging findings from across the human and social sciences, the present article aims to demonstrate the relevance and applicability of the study of collective rituals in the field of sport psychology. Specifically, the purpose is two-fold: to consider the application of an existing conceptual definition of collective ritual to behaviours in team sports; and to demonstrate the utility of this common conceptual basis by exploring how previous research on the topic applies to two growing areas in the group dynamics literature; namely, team resilience and communal coping.

\section{Defining collective ritual}

Many social science fields have long been interested in the study of rituals at the individual and collective levels (Bell, 1992; Boyer \& Liénard, 2006; Durkheim, 1915; Freud, 1963; Humphrey \& Laidlaw, 1994; Van Gennep, 1960). As such, conceptual definitions of ritual in general have varied greatly over the history of its study (Goody, 1961). To address this issue, a recent integrative review proposed a definition that seems appropriately applicable to research in the field of sport psychology. Hobson, Schroeder, Risen, Xygalatas \& Inzlicht (2017) posit that rituals (both individual and collective) are made up of three specific criteria. For a behaviour to be considered a ritual, it must (a) involve predefined sequences of physical actions, usually ordered, sequenced, and repetitive; (b) hold some symbolism or psychological meaning to those performing it; and (c) contain elements lacking direct instrumental purpose. Using these criteria, one can categorize rituals as distinct from other similar patterns of thoughts and actions. For example, by this definition an athlete's possession of a good luck charm would not constitute a ritual as it lacks a predefined sequence of physical action. As such, it would be better categorized by the term superstition. Further, while the All Blacks' haka would constitute a ritual, a warm-up stretching regimen would not. This is because warming up serves the instrumental purpose of preparing muscles for action to preventing injury (Witvrouw, Mahieu, Danneels, \& McNair, 2004), and would therefore be better characterized by the term routine. Though these terms may seem conceptually similar, they are distinguishable in important ways. Clarifying these distinguishing features is critical for having a common conceptual basis in order to better understand the specific and nuanced purposes collective rituals serve in team sports, and how those may differ from other related thoughts and behaviours.

Rituals are considered collective when they are performed at the group level. Drawing on cultural anthropological research, Whitehouse \& Lanman (2014) suggest that two main types of collective rituals have historically arisen in social groups, each with their own distinct social functions: doctrinal and imagistic practices. Doctrinal practices are less aversive, frequently repeated, and emphasize "credibility-enhancing displays for beliefs, ideologies and values" (Whitehouse \& Lanman, 2014, p. 6) to promote group identification and social cohesion. This type of collective action aligns with what in sport might be called a pregame ritual (e.g., a pregame cheer). Imagistic practices are less frequent (occurring sometimes as rarely as once a lifetime), involve behaviours characterized by high levels of dysphoric arousal, and have been more typical of small groups facing high risks where the likelihood of defection is increased (Atkinson \& Whitehouse, 2011; Turchin, Whitehouse, Francois, Slingerland, \& Collard, 2012; Whitehouse, 2004). Examples of imagistic practices are often enacted by street gangs when initiating new members. For instance, gang members have described the process of being "jumped in" whereby the newcomer must take repeated physical beatings to demonstrate their commitment to the group (Descormiers \& Corrado, 2016). Though typically less extreme in sports contexts, it would seem team initiation rituals (e.g., hazing) would be a type of behaviour that falls under this category.

Even though by definition their constituent actions lack explicit instrumental purpose (Hobson, Schroeder, et al., 2017), collective rituals have been found to serve important psychosocial functions. In a review of the evolutionary-sciences literature, Watson-Jones \& Legare (2016) posit that collective rituals have historically arisen as a means of managing the adaptive problems associated with group behaviour by helping to identify group members, ensuring group commitment, facilitating cooperation, and maintaining cohesion. Frequently repeated collective rituals (i.e., doctrinal practices) are associated with a group's norms and become a routinized and stable part of group members' semantic memories (Whitehouse \& Lanman, 2014). Costlier ritual displays (such as the dysphoric actions characteristic of imagistic practices) are enacted as a means of confirming one's commitment to the group in a way that verbal affirmations cannot (Henrich, 2009). Actions speak louder than words: while one might try to verbally deceive their fellow group members in terms of their commitment, "willingly enduring a painful initiation rite put credibility to one's words" (Rossano, 2012, 529). Though it is possible that the collective rituals occurring in team sports operate via similar functional mechanisms, few studies have taken to investigating this area of research.

In considering the research from other fields, there is reason to believe collective rituals can serve adaptive psychosocial functions in team sports. They have been 
posited to enhance affiliation between participating members and help share important cultural knowledge about the group (e.g., group norms; Hobson, Schroeder, et al., 2017). Recent developments in sport psychology research have uncovered the importance of understanding how groups and teams draw on their collective psychosocial resources to overcome adversity (Decroos, et al., 2017; Morgan, Fletcher, \& Sarkar, 2013, 2015, 2017). Two growing topics of interest in this area where collective rituals may play a potential role are team resilience and communal coping. Though there is a lack of research on collective rituals in sport specifically, the following sections will draw on existing evidence from other related fields (e.g., cultural anthropology, social psychology) to shed light on why these behaviours might be so prevalent in team sports. First, the potential role of collective rituals in fostering team resilience will be examined. Then, the use of collective rituals as communal coping strategies to deal with group stressors will be considered.

\section{Collective rituals and team resilience}

As all athletes encounter roadblocks in some form over the course of their careers, being able to overcome negative obstacles is an important component of success. Generally, the term resilience refers to an individual or group's ability to deal with hindrances and/or recover from setbacks (Fletcher \& Sarkar, 2012). Though much of the research on resilience in sport has investigated it at the level of the individual (Fletcher \& Sarkar, 2012; Galli \& Vealey, 2008; Gucciardi, Jackson, Coulter, \& Mallett, 2011; Sarkar \& Fletcher, 2014), there has been growing interest in how it manifests at the team level, examining how collective psychosocial processes can bolster against the potential negative effects of adverse situations (Decroos, et al., 2017; Morgan, et al., 2013, 2015, 2017). A qualitative investigation in elite sport identified four main characteristics of team resilience: group structure, mastery approaches, social capital and collective efficacy (Morgan, et al., 2013). Using these identified themes as a framework, the role of collective rituals in team resilience in sport will be examined, specifically within the themes of group structure and social capital. We suggest that by priming individual athletes with their team's identity, collective rituals help to solidify a group's structure. Furthermore, by strengthening the bonds between teammates, they can contribute to a team's social capital.

\subsection{Group structure}

According to Morgan et al. (2013), group structure "refers to the conventions that shape group norms and roles and involve both psychosocial and physical aspects" (p. 552). Under group structure, the higher-order themes of "formal structures", "group norms and values", and "communication channels" were identified. Namely, a resilient team has the formal structures in place to mobilize groups and resources when necessary, share an implicit vision for their team that provides a sense of purpose, and can communicate clearly when stressors arise (Morgan, et al., 2013). In the unpredictable arena of sport, these pre-established and unspoken understandings shared by teammates allow for individual athletes to make decisions that operate in coordination with their playing partners. In performance contexts, neurophysiological evidence suggests that this type of structural organization is important in preparatory stages of performance, but less organization (and more flexibility) is beneficial during actual performance (Stevens, Galloway, Lamb, Steed, \& Lamb, 2015).

Doctrinal collective rituals play a role in cognitively aligning performers with the structures and values of their team. According to the Self-Categorization Theory (Turner, Hogg, Oakes, Reicher, \& Wetherell, 1987), individuals belong to several social categories (e.g., athlete, family member, student) with the most situationally salient one driving thoughts and behaviours (Reynolds, 2017). For instance, upon entering a hockey arena, a student-athlete's academic identity takes a back seat as the individual category of "hockey player" becomes salient. This shift in identity serves the functional purpose of facilitating thoughts and behaviours relevant to the social norms of this particular context. For example, on the ice, being calm and contemplative is not as beneficial as it might be in a lecture hall. Therefore, priming one's salient identity as a hockey player benefits performance as it brings with it the instrumentally-desirable states associated with playing hockey. Self-categorization can also occur at different group levels (Brewer \& Gardner, 1996). A hockey player is not just an individual, but a member of a hockey team with its own set of social norms. It has been posited that every doctrinal ritual performance primes group members with the values of their current group, making them more likely follow this specific team's social norms (Rossano, 2012).

As athletes typically transition from one team to another throughout their careers, they experience a variety of team identities, norms, and values. Collective rituals may therefore also play an important role in the socialization and integration of new incoming team members. Though empirical research on this topic is lacking in the sports setting specifically, supportive evidence has emerged from experimental studies of participants randomly assigned to minimal groups. For instance, novel rituals have been experimentally demonstrated to lead to intergroup biases, as indicated by higher amounts of money being shared with in-group members during an economic trust game in lab settings (Hobson, Gino, et al., 2017). It is possible that these effects on group structure stem from the ritualized actions themselves. To determine if this is the case, Wen, Herrmann \& Legare (2016) separated children into two minimal groups and had them participate in a necklace building activity. While one group was instructed to build their necklaces in a less structured manner, the other was prompted to follow instructions typical of ritualistic behaviour (e.g., "Next touch a green square to your head and string it on... Next clap your hands three times. Then string on a green circle"; 
p. 56). The synchronized and repeated actions of the ritual group were associated with a significant increase in selfreported in-group affiliation in post-test measures. Though further research is needed to determine if the results replicate in sports settings, these findings provide preliminary evidence suggestive of a synergistic effect of collective rituals on group structures, having implications for team sports. By bolstering in-group affiliation in minimal groups, collective rituals may play a role in socializing new players to a team.

\subsection{Social capital}

Under the category of social capital, Morgan et al. (2013) identified the subtheme of group identity, pertaining in part to the emotional bonds shared between teammates. One particular quote reflects the strength of an athlete's attachment to their peers; bonds between teammates in resilient teams are so strong that "you would throw your life down for them" (Morgan, et al., 2013, p. $555)$. The emphasis with which this athlete describes their connection to the group is reminiscent of identity fusion. Identity fusion has been defined as a visceral feeling of oneness with one's group associated with an increased permeability of the boundary separating the personal and the social self, thereby motivating them to do as much for the group as they would for themselves (Swann, Jetten, Gómez, Whitehouse, \& Bastian, 2012). In times of distress, identity fused individuals have reported to be more willing to fight or even die for their group, especially when their group identity is activated (Swann, Gómez, Seyle, Morales, \& Huici, 2009).

If indeed resilient teams are characterized by having fused identities among teammates, generating identity fusion might be a mechanism through which collective rituals influence team resilience. A recent study examining imagistic practices in Brazilian Jiu Jitsu (BJJ) sought to determine the effects of dysphoric high-arousal rituals (i.e., imagistic practices) on social cohesion and identity fusion (Kavanagh, Jong, McKay, \& Whitehouse, 2018). In BJJ, there exists a rare promotional ceremony where the promoted individuals must walk through the gauntlet (a line of their training partners whipping them with belts); the practice is considered somewhat controversial and has been denounced by certain schools and instructors. Kavanagh et al. (2018) found that this particular imagistic practice was associated with identity fusion only if it was considered to be a positive affective experience. When the promotional ceremony experience was considered affectively negative, no such relationship was found. These findings reveal collective rituals' potential to increase identity fusion in a sports setting, if they are viewed as a positive emotional experience. The visceral feeling of oneness with the group associated with identity fusion (Swann, et al., 2012) is similar to the way Morgan et al. (2013) characterized relationships in resilient sports teams. As collective rituals may evidently play a role in bolstering identity fusion in sports (Kavanagh, et al., 2018), it is possible that identity fusion may mediate the relationship between collective rituals and team resilience. Future longitudinal and experimental research is needed to further explore the associations between imagistic collective rituals and identity fusion, and how identity fusion contributes to the resilience of sport teams.

Another aspect of social capital identified by Morgan et al. (2013) was perceived social support, where resilient teams are characterized by players who subjectively feel like they would be supported by teammates in times of need. Indeed, perceived social support has previously been identified as a psychological factor in individual resilience amongst Olympic champions (Fletcher \& Sarkar, 2012). Though limited research exists on the effects of collective rituals on perceptions of social support in sport specifically, the topic has been investigated in the context of spiritual and religious collective gatherings. Participating in collective rituals after traumatic events has been found to increase perceived social support (Páez, Basabe, Ubillos, \& González-Castro, 2007). This has important implications in sport as perceived social support has been found to influence athletes' self-confidence (Rees \& Freeman, 2007). Further research is required to determine if collective ritual participation similarly helps foster perceived social support in sports teams.

Finally, the third subtheme under social capital identified by Morgan et al. (2013) was prosocial interactions and pertained to the selflessness and positive interactions between teammates on resilient teams. Anthropologists have long theorized that collective rituals play an important role in in-group cooperation (Durkheim, 1915). Indeed, religious studies have found that frequency of doctrinal practice participation predicts cooperative behaviour in economic games with in-group members (Ruffle \& Sosis, 2007; Sosis \& Ruffle, 2003). Also, if rituals involve more synchronous body movements, they are more likely to enhance prosocial attitudes towards the group (Fischer, et al., 2013). Similarly, for imagistic practices, collective ritual participants have been found to donate more money to their in-group after they engage in a higher-ordeal (i.e., costlier to the self) as compared to low-ordeal rituals, with the level of pain correlating with the amount donated (Xygalatas, et al., 2013). If this is the case in sports, teams who perform more frequent and synchronous collective rituals should demonstrate greater generosity and prosociality between teammates, possibly resulting in greater team resilience. Though in considering the implications of these findings, it is important to keep athletes' well-being in mind. For example, even if forcing athletes to demonstrate their commitment to the team by having them run sprints until they vomit might potentially result in an increase in prosocial behaviours between teammates, it is hardly worth the harm that this type of treatment will cause the individual athletes themselves.

The evidence here supports the idea of collective rituals' potential role in promoting team resilience. At the level of a group's structure, they may help to align individuals with the values of their team and socialize 
new incoming members creating a more cohesive unit. In terms of social capital, collective rituals may generate identity fusion and foster prosocial interactions, thereby having an effect on the group environment. To date, there has been no research examining the link between collective rituals, mastery approaches, and collective efficacy, and future inquiries on the relationship between collective rituals and team resilience should take these components into consideration. There is also reason to believe that the actual performance of collective rituals can have a positive psychological effect on each individual performer, particularly in response to stressors. In the following section, the potential employment of collective rituals as communal coping strategies will be examined.

\section{Collective rituals and communal coping}

Sport psychology researchers have typically examined the topic of stress and coping from an intrapersonal perspective (Tamminen \& Gaudreau, 2014). This work has mainly been conducted from the framework of Lazarus's cognitive-motivational-relational theory (CMRT) of emotions that posits that athletes construct relational meanings in their appraisals of stressors that stem from the transactional processes between personal factors and the environmental demands of specific situation (Lazarus, 1999, 2000). In this theoretical framework, coping is understood to be an individual's "cognitive and behavioural efforts to manage specific external and/or internal demands that are appraised as taxing or exceeding the resources of the person" (Lazarus \& Folkman, 1984, p. 141). However, as athletes tend to experience stressors and engage in coping strategies in social situations, there has been a growing interest in how these processes occur at the interpersonal or team level.

Communal coping is the cooperative process by which groups of individuals manage stressors encountered either by a group or its constituent members (Lyons, Mickelson, Sullivan, \& Coyne, 1998). In these situations, individual and collective efforts are made to mobilize resources to address the adaptive challenges at hand (Lyons, et al., 1998; Tamminen \& Gaudreau, 2014). This is indeed the case in team sports where collective strategies are implemented to communally manage emotions (Crocker, Tamminen, \& Gaudreau, 2015; Friesen, Devonport, Sellars, \& Lane, 2013, 2015; Friesen, Lane, Devonport, Sellars, Stanley, \& Beedie, 2013; Tamminen \& Crocker, 2013). In a recent qualitative study of the topic, Leprince, d'Arripe-Longueville \& Doron (2018) explored athletes' perceptions of shared stressors and communal coping strategies using semistructured interviews. Leprince et al. (2018) found that athletes competing in team sports do indeed appraise mutual problems as shared sources of stress. In response to these shared stressors, the authors found that sports teams engage in communal coping strategies that tend to fall into four main dimensions: problem-focused communal efforts (e.g., information sharing, refocusing), relationship-focused coping (e.g., motivational support, social joining), communal management of emotions (e.g., interpersonal emotion regulation, reassurance), and communal goal withdrawal (e.g., task-disengagement, venting of emotions). Though this was a preliminary investigation of the topic in sports teams, similar findings have been found in research examining communal coping between competitive youth athletes and their parents (Neely, McHugh, Dunn, \& Holt, 2017).

Collective rituals themselves can be used as a communal coping strategy at the team level to deal with stressors that arise before, during, and after competition. Although rituals by definition lack overt instrumental purpose (Hobson, Schroeder, et al., 2017), this might not always be the case in sports. In fact, research is beginning to reveal how athletes and other performers use this type of behaviour to prevent or overcome stressors, and there has been a growing interest in identifying the mechanisms through which these behaviours operate. Drawing on the applicable research from the existing literature in neighbouring social science fields, collective rituals' alignment with the communal coping framework of Lyons et al. (1998) and the dimensions subsequently identified by Leprince et al. (2018) will be examined. Specifically, collective rituals' potential implementation as a means of communally managing emotions will be discussed.

Collective rituals have been found to influence the emotional climate in which the group is operating (Kanyangara, Rimé, Philippot, \& Yzerbyt, 2007) and, as such, may therefore help athletes communally manage their emotions. However, it is possible that some of these mechanisms operate outside of the athlete's conscious awareness. Drawing from the findings of ethnographic work, Rappaport (1971) noted the regulatory function of rituals and proposed that they operate as a cybernetic system whereby ritualistic behaviour is triggered when a suboptimal threshold of a variable (or series of variables) is reached. Hobson, Schroeder et al. (2017) posited that if this is indeed the case, experiencing a deficit (or abundance) of a positive (or negative) emotion should elicit more instances of ritualistic behaviour. Following this logic, when athletes compete in events with higher stakes, they should be more likely to engage in collective rituals as the pressure mounts to potentially debilitating levels. Indeed, athletes have been found to increasingly engage in rituals when winning demands or team pressure increases (Dodo, Lyoka, Chetty, \& Goon, 2015). Also in support of the cybernetic model, ritual commitment has been found to positively correlate with uncertainty and game importance (Brevers, Dan, Noël, \& Nils, 2011).

Many collective rituals take place before performances, perhaps due to the mounting pressure athletes perceive before competing. Whether or not athletes are consciously aware of it, these behaviours have been found to buffer against negative affective outcomes. For instance, at the individual level, having participants 
perform a previously-learned arbitrary ritual was found to reduce error-related negativity (ERN; i.e., a neural response to performance failures) in subsequent performance tasks (Hobson, Bonk, \& Inzlicht, 2017). These findings are suggestive of rituals' potential utility in the coping process because higher ERN responses have been associated with negative affective experiences (Hajcak, McDonald, \& Simons, 2004) and state anxiety (Tullett, Kay, \& Inzlicht, 2015). ERN amplitudes have also been shown to decrease when negative emotional responses to errors are down-regulated (Hobson, Saunders, Al-Khindi, \& Inzlicht, 2014). Though this research has promising implications in sport performance, it was only conducted at the individual level. Future research is needed to determine how the group element of collective rituals influences group members' abilities to cope with errors.

Specific to group-level behaviours, evidence from physiological studies also suggests collective rituals can influence coping. Synchronized actions, a component typical of collective rituals, have been found to lead to increased endorphin release in dancers (Tarr, Launay, Cohen, \& Dunbar, 2015) and musical performers (Weinstein, Launay, Pearce, Dunbar, \& Stewart, 2016). In turn, increased endorphin release plays a key role in stress-reduction (Bali, Randhawa, \& Jaggi, 2015). When the All Blacks are performing their war cry and dance in unison, they are not only striking fear in the hearts of their opponents, but also bolstering their physiological resources to respond to stressors. Similar effects have been found in other sport contexts. Training in groups leads to a higher endorphin release as opposed to training solo (Cohen, Ejsmond-Frey, Knight, \& Dunbar, 2010), regardless if training partners are teammates or strangers (Sullivan \& Rickers, 2012). It is possible that collective rituals have a similar effect in team sports through the use of synchronous chants and movements. Furthermore, it is also possible that relationships exist between collective rituals and the other identified subcategories of communal coping (i.e., problem-focused communal efforts, relationship-focused coping, and communal goal withdrawal; Leprince, et al., 2018). However, like stress and coping, most research on the topic of rituals in sport been conducted at the level of the individual athlete (Bartošová, Burešová, Dacerová, \& Valcová, 2017). As such, further research is needed to identify if and how these concepts may be related.

The implementation of collective rituals seems to have adaptive properties that may prove beneficial in dealing with the uncertainties of athletic competition. It appears that they can play a preventative role, preparing a group for adversity by strengthening its structure and social capital. Similarly, they may work in a more regulatory manner, arising in response to stressors and reducing their ill-effects. However, they can also have maladaptive properties that can be harmful (to both performances and performers themselves) when taken to the extreme. Some of problematic outcomes of collective rituals will now be considered in terms of how they may apply to team sport settings.

\section{Maladaptive outcomes of collective rituals}

Collective rituals should not be considered exclusively in terms of their adaptive outcomes. If they are indeed an effective means of boosting resilience and managing stressors, overreliance on them can become problematic. For instance, once a team becomes habituated to the palliative properties of their rituals, in order to maintain the same level of beneficial outcomes they may need to increase the length and complexity of their action sequences and the rigidity with which they are followed (Hobson, Schroeder, et al., 2017). The longer and more complicated a team's collective ritual is, the less likely they are to be able to stick to the script verbatim. Unpredictability abounds in athletic performances and being able to adapt to unforeseeable changes is fundamentally important to success. Thus, if a team becomes overdependent on their ritual, it can become a source of anxiety itself. Furthermore, athletes may experience negative affective responses in circumstances when they are prevented from engaging in their ritual. Highly repeated (i.e., doctrinal) rituals have been posited to arise in response to an overactive mental precaution system geared towards detecting inferred threats (Boyer \& Liénard, 2006). As such, the inability to engage in ritualistic behaviour makes it easier for intrusive thoughts to come to consciousness (similar to symptoms of pathological conditions like OCD; Boyer \& Liénard, 2008) which can be detrimental to sports performances.

Aside from performance outcomes, collective rituals may lead to aversive consequences for athletes' well-being. For instance, when dealing with imagistic practices, researchers and practitioners must be mindful of the abusive nature of these acts in team sports. Initiation rituals (or hazing) are particularly concerning because of their prevalence in elite sport (Crow \& Macintosh, 2009; Hinkle, Smith, \& Stellino, 2007; Hoover \& Pollard, 2000). Hazing entails any degrading and/or dangerous activity incoming group members are expected to take part in, sometimes even against their will (Hoover \& Pollard, 2000). These activities may include being yelled and cursed at, acting as a servant, forced excessive consumption of alcohol, simulated sexual acts, as well as physical, emotional, or sexual assault (Hinkle, Smith, \& Stellino, 2007). These behaviours are considered to be a form of social bullying (Stirling, 2009; Stirling, Bridges, Cruz, \& Mountjoy, 2011), or even sexual abuse (Kirby \& Wintrup, 2002) when taken to the extreme and can result in depression, anxiety, or posttraumatic stress (LaFerney, 2016). Yet despite efforts to discourage the practice, hazing remains persistent in sports (Crow \& Macintosh, 2009).

Here, future research in sports science should seek to determine if and how initiation rituals should continue to be implemented. The National College Athletic Association's (NCAA) hazing prevention handbook suggests that hazing practices should be discouraged while teambuilding activities should be emphasized (NCAA, 2007). Not only will this help prevent negative experiences for 
athletes, it may even increase collective rituals' effectiveness in producing desired results. Indeed, only affectively positive experiences of imagistic rituals in sport have been found to be positively related with identity fusion (Kavanagh, et al., 2018). From an applied perspective, more knowledge on this topic will help to inform how coaches and practitioners can reduce harm and increase positive experiences in their respective sports.

\section{Conclusion and future directions}

Collective rituals are cultural universals, appearing in all forms of human practices. From tribal hunters, to religious believers, to athletic competitors; it seems that when groups of individuals band together, collective rituals tend to emerge. From an evolutionary perspective, they facilitate group living by helping to identify group members, ensuring group commitment, and promoting collaboration and cohesion between group members (Watson-Jones \& Legare, 2016). As these mechanisms have implications in team sports settings, group dynamics researchers in sport psychology stand to benefit from the research on collective rituals from diverse fields of human studies. By drawing on the literature from across the human and social sciences, the applicability of an existing definition of collective ritual was examined within the field of sport psychology, and relevant findings were explored within frameworks of team resilience and communal coping. It is important to reiterate that the purpose of this article was not to conduct an exhaustive review of every topic in the group dynamics literature relevant to collective rituals in sports. Rather, the purpose was to provide a common conceptual basis from which collective rituals in sport can be examined. Operating from this common starting point allows for the exploration and application of relevant literature on collective ritual from neighbouring fields in the social sciences to the context of team sports. Though promising links can be drawn between collective ritual research and group dynamics, further investigation is needed to determine if the results do in fact carry over into the realm of sport.

Though only a selective list of topics in group dynamics were reviewed here in relation to collective rituals, there are many more avenues ripe for further investigation. For instance, researchers studying collective activity in sport have taken to exploring how teammates coordinate their actions based on pre-meditated plans and adapt to shared perceptions of situational cues in performance settings (e.g., Bourbousson, Poizat, Saury \& Sève, 2012; De Keukelaere, Kermarrec, Bossard, Pasco, \& De Loor, 2013; Gesbert, Durny, \& Hauw, 2017). As collective rituals seem to play a role in many aspects of group activity, it could be fruitful for future research to examine collective rituals' influence on these collective processes. It may also be beneficial to consider what role the individual team member and their personality plays in this relationship. Another area of growing interest in which collective rituals could have potential relevance is the study of placebo effects in sport and exercise (e.g., Beedie, et al., 2017, 2018) because athletes' rituals and superstitions have long been hypothesized to be acting as placebos (Neil, 1980). As collective rituals may share similar underlying mechanisms to other placebos in team sport settings, further investigations of these topic could prove to be mutually beneficial.

The relationships between collective rituals, team resilience, and performance outcomes are also areas in which deeper explorations are needed. For instance, experimentally implementing and manipulating collective rituals in a sports setting will help to determine the causal mechanisms behind some of the correlational findings described here. Also, longitudinal research can be used to further explore the degree to which collective rituals play a role in team resilience, and address some of the questions that may arise in an applied environment and how these may develop over the course of time. From an applied perspective, this line of research has important implications for both athlete well-being and performance improvement, as more resilient teams are argued to be better equipped for dealing with stressors, setbacks, and challenges when they arise (Fletcher \& Sarkar, 2012; Morgan, et al., 2013, 2015, 2017), which can be beneficial for the mental health of team members (Yamada, Kawata, Kamimura, \& Horisawa, 2017).

There is reason to believe collective rituals can be implemented as communal coping strategies. One problem with attempting to study them within a communal coping framework (Lyons, et al., 1998) is their causal opacity. The act of coping involves the instrumental cognitive and behavioural actions implemented to deal with source of stress (Lazarus \& Folkman, 1984). However, sport teams can engage in these behaviours to combat stressors without consciously knowing the adaptive benefits they derive from them. As such, a team's collective ritual may not come to mind when an athlete is prompted to rate their collective coping strategies on a survey or discuss them in a semi-structured interview, even though they may serve as a strategy to help athletes cope with stressors communally. Future studies on the topic must keep this in consideration.

Finally, the maladaptive side of collective rituals also requires more empirical inquiry. Further studying imagistic rituals in sport can help us better understand why such seemingly maladaptive behaviours recur so frequently. Despite their suggested adaptive outcomes, minimizing the amount of harmful behaviours athletes engage in (such as hazing) should always be a priority. Future research on collective rituals in sport can help determine which situations are more likely to elicit instances of such behaviour. For instance, dysphoric rituals have historically arisen in groups facing higher risks (Turchin, et al., 2012); thus, it would be worth examining whether these behaviours are more typical in more dangerous and physically violent sports. Shedding light on when and how these behaviours arise is an important step in preventing their harmful consequences and informing policy decisions for sport organizations (e.g., NCAA, 2007). 
Links drawn from research in other contexts helps to illuminate our understanding of how and why these behaviours recur so frequently and what consequences they may bring about. They shed light on how and why athletes can benefit or be hindered by participating in a team's collective ritual. From an applied standpoint, the implications are significant. On the one hand, it appears that collective rituals have the potential to positively influence a team's group dynamics by bolstering team resilience and helping to cope with team stressors. However, if left unchecked, rituals themselves could become the sources of stress and harm. With a deeper understanding of these behaviours in team sport contexts specifically, coaches and practitioners will be better able to distinguish the helpful from the harmful. Further research will help them strike this balance.

\section{Author Contribution Statement}

Author 1, Author 2, and Author 4 contributed to the development of the idea for the manuscript, the writing, editing, and the revisions to the manuscript. Author 3 contributed to the revisions to the manuscript.

Acknowledgments. We would like to acknowledge the efforts of the reviewers whose feedback helped improve the quality of the manuscript.

\section{References}

Atkinson, Q.D., \& Whitehouse, H. (2011). The cultural morphospace of ritual form: Examining modes of religiosity cross-culturally. Evolution and Human Behavior, 32, 50-62. doi: 10.1016/j.evolhumbehav.2010.09.002.

Bali, A., Randhawa, P.K., \& Jaggi, A.S. (2015). Stress and opioids: Role of opioids in modulating stress-related behavior and effect of stress on morphine conditioned place preference. Neuroscience \& Biobehavioral Reviews, 51, 138-150. doi: 10.1016/j.neubiorev.2014.12.018.

Bartošová, K., Burešová, I., Dacerová, V., \& Valcová, A. (2017). Rituals in sport. Kinesiologia Slovenica, 13, 5-13.

Beedie, C., Whyte, G., Lane, A.M., Cohen, E., Raglin, J., Hurst, P., Coleman, D., \& Foad, A. (2017). 'Caution this treatment is a placebo. It might work, but it might not': Why emerging mechanistic evidence for placebo effects does not legitimise complementary and alternative medicines in sport. British Journal of Sports Medicine, O(1), 1-2. doi: 10.1136/bjsports2017-097747.

Beedie, C., Benedetti, F., Barbiani, D., Camerone, E., Cohen, E., Coleman, D., Davis, A., Elsworth-Edelsten, C., Flowers, E. Foad, A., Harvey, S., Hettinga, F., Hurst, P., Lane, A., Lindheimer, J., Raglin, J., Roelands, B., Schiphof-Godart, L., \& Szabo, A. (2018). Consensus statement on placebo effects in sport and exercise: The need for conceptual clarity, methodological rigour, and the elucidation of neurobiological mechanisms. European Journal of Sport Science, 18(10), 1383-1389. doi: 10.1080/17461391.2018.1496144.

Bell, C. (1992). Ritual theory, ritual practice. New York, NY: Oxford University Press.
Bourbousson, J., Poizat, G., Saury, J., \& Sève, C. (2012). Temporal aspects of team cognition: A case study on concerns sharing within basketball. Journal of Applied Sport Psychology, 24, 224-241. doi: 10.1080/10413200.2011.630059.

Boyer, P., \& Liénard, P. (2006). Why ritualized behavior? Precaution systems and action parsing in developmental, pathological and cultural rituals. Behavioral and Brain Sciences, 29, 595-650. doi: 10.1017/S0140525X06009332.

Boyer, P, \& Liénard, P. (2008). Ritual behavior in obsessed and normal individuals: Moderating anxiety and reorganizing the flow of action. Current Directions in Psychological Science, 17, 291-294. doi: 10.1111/j.1467-8721.2008.00592.x.

Brevers, D., Dan, B., Noël, X., \& Nils, F. (2011). Sport superstitions: Mediation of psychological tension on nonprofessional sportsmen's superstitious rituals. Journal of Sport Behavior, 34, 3-24.

Brewer, M.B., \& Gardner, W. (1996). Who is this "We"? Levels of collective identity and self representations. Journal of Personality and Social Psychology, 71, 83-93. doi: 10.1037/ 0022-3514.71.1.83.

Cohen, E.E.A., Ejsmond-Frey, R., Knight, N., \& Dunbar, R.I.M. (2010). Rowers' high: Behavioural synchrony is correlated with elevated pain thresholds. Biology Letters, 6, 106-108. doi: $10.1098 /$ rsbl.2009.0670.

Crocker, P.R.E., Tamminen, K.A., \& Gaudreau, P. (2015). Coping in sport. In S. Hanton \& S. Mellalieu (Eds.), Contemporary advances in sport psychology: A review 2867. New York, NY: Routledge.

Crow, R.B., \& Macintosh, E.W. (2009). Conceptualizing a meaningful definition of hazing in sport. European Sport Management Quarterly, 9, 433-451. doi: 10.1080/ 16184740903331937.

Decroos, S., Lines, R.L.J., Morgan, P.B.C., Fletcher, D., Sarkar, M., Fransen, K., Boen, F., \& Vande Broek, G. (2017). Development and validation of the characteristics of resilience in Sports Teams Inventory. Sport, Exercise, and Performance Psychology, 6, 158-178. doi: 10.1037/ spy0000089.

De Keukelaere, C., Kermarrec, G., Bossard, C., Pasco, D., \& De Loor, P. (2013). Formes, contenus et évolution du partage au sein d'une équipe de sport de haut niveau. Le Travail Humain, 76, 227-255. doi: 10.3917/th.763.0227.

Descormiers, K., \& Corrado, R.R. (2016). The right to belong: Individual motives and youth gang initiation rites. Deviant Behavior, 3\%, 1341-1359. doi: 10.1080/ 01639625.2016.1177390.

Dodo, E.O., Lyoka, P.A., Chetty, I.G., \& Goon, D.T. (2015). An exploration of the perceptions of spiritual rituals among elite players and coaches associated with religiosity or psychological variables: Sport psychology. African Journal for Physical Health Education, Recreation and Dance, 21, 103-127.

Durkheim, E. (1915). The elementary forms of religious life. New York, NY: The Free Press.

Fischer, R., Callander, R., Reddish, P., \& Bulbulia, J. (2013). How do rituals affect cooperation? An experimental field study comparing nine ritual types. Human Nature, 24, 115125. doi: $10.1007 / \mathrm{s} 12110-013-9167-y$.

Fletcher, D., \& Sarkar, M. (2012). A grounded theory of psychological resilience in Olympic champions. Psychology of Sport Exercise, 13, 669-678. doi: 10.1016/j. psychsport.2012.04.007.

Freud, S. (1963). Character and Culture. New York, NY: Collier Books. 
Friesen, A.P., Devonport, T.J., Lane, A.M., \& Sellars, C.N. (2013). A narrative account of decision-making and interpersonal emotion regulation using a social-functional approach to emotions. International Journal of Sport and Exercise Psychology, 11, 203-214. doi: 10.1080/1612197X.2013.773664.

Friesen, A.P., Lane, A.M., Devonport, T.J., Sellars, C.N., Stanley, D.N., \& Beedie, C.J. (2013). Emotion in sport: Considering interpersonal regulation strategies. International Review of Sport and Exercise Psychology, 6, 139-154. doi: 10.1080/1750984X.2012.742921.

Friesen, A.P., Devonport, T.J., Lane, A.M., \& Sellars, C.N. (2015). Interpersonal emotion regulation: An intervention case study with a professional ice hockey team. Athletic Insight, $7(2), 129-142$.

Galli, N., \& Vealey, R.S. (2008). "Bouncing back" from adversity: Athletes' experiences of resilience. The Sport Psychologist, 22, 316-335. doi: 10.1123/tsp.22.3.316.

Gesbert, V., Durny, A., \& Hauw, D. (2017). How do soccer players adjust their activity in team coordination? An enactive phenomenological analysis. Frontiers in Psychology, 8, 854. doi: 10.3389/fpsyg.2017.00854.

Goody, J. (1961). Religion and ritual: The definitional problem. The British Journal of Sociology, 12, 142-164.

Gucciardi, D.F., Jackson, B., Coulter, T.J., \& Mallett, C.J. (2011). The Connor-Davidson Resilience Scale (CD-RISC): Dimensionality and age-related measurement invariance with Australian cricketers. Psychology of Sport and Exercise, 12, 423-433. doi: 10.1016/j.psychsport.2011.02.005.

Hajcak, G., McDonald, N., \& Simons, R.F. (2004). Error-related psychophysiology and negative affect. Brain and Cognition, 56, 189-197. doi: 10.1016/j.bandc.2003.11.001.

Henrich, J. (2009). The evolution of costly displays, cooperation, and religion: Credibility enhancing displays and their implications for cultural evolution. Evolution and Human Behavior, 30, 244-260. doi: 10.1016/j.evolhumbehav.2009.03.005.

Hinkle, S., Smith, S.L., \& Stellino, M.B. (2007) Cognitive dissonance in athletic hazing: The roles of commitment and athletic identity. Journal of Sport \& Exercise Psychology (Suppl.), 29, S169-S170.

Hobson, N.M., Saunders, B., Al-Khindi, T., \& Inzlicht, M. (2014). Emotion down-regulation diminishes cognitive control: A neurophysiological investigation. Emotion, 14, 10141026. doi: $10.1037 / \mathrm{a} 0038028$.

Hobson, N.M., Bonk, D., \& Inzlicht, M. (2017). Rituals decrease the neural response to performance failure. PeerJ, 5, e3363. doi: $10.7717 /$ peerj.3363.

Hobson, N.M., Gino, F., Norton, M.I., \& Inzlicht, M. (2017). When novel rituals lead to intergroup bias: Evidence from economic games and neurophysiology. Psychological Science, 28, 733-750. doi: 10.1177/0956797617695099.

Hobson, N.M., Schroeder, J., Risen, J.L., Xygalatas, D., \& Inzlicht, M. (2017). The psychology of rituals: An integrative review and process-based framework. Personality and Social Psychology Review. doi: 10.1177/1088868317734944.

Hoover, N.C., \& Pollard, N. (2000). Initiation rites in American high schools: A national survey. New York: Alfred University.

Humphrey, C., \& Laidlaw, J. (1994). The archetypal actions of ritual: A theory of ritual illustrated by the Jain rite of worship. Oxford, England: Clarendon Press.

Jackson, S.J. \& Hokowhitu, B. (2002). Sports, tribes, and technology: The New Zealand All Blacks haka and the politics of identity. Journal of Sport and Social Issues, 26, 125-139. doi: 10.1177/0193723502262002.

Kanyangara, P, Rimé, B., Philippot, P., \& Yzerbyt, V. (2007). Collective rituals, emotional climate and intergroup perception: Participation in "Gacaca" tribunals and assimilation of the Rwandan genocide. Journal of Social Issues, 63, 387-403. doi: 10.1111/j.1540-4560.2007.00515.x.
Kavanagh, C.M., Jong, J., McKay, R., \& Whitehouse, H. (2018). Positive experiences of high arousal martial arts rituals are linked to identity fusion and costly progroup actions. European Journal of Social Psychology. doi: 10.1002/ejsp.2514.

Kirby, S.L., \& Wintrup, G. (2002). Running the gauntlet: An examination of initiation/hazing and sexual abuse in sport. Journal of Sexual Aggression, 8, 49-68. doi: 10.1080/ 13552600208413339.

LaFerney, M.C. (2016). You can help victims of hazing recover from psychological and physical harm. Current Psychiatry, $15,72-73$.

Lazarus, R.S. (1999). Stress and emotion: A new synthesis. New York: Springer Publishing.

Lazarus, R.S. (2000). Cognitive-motivational-relational theory of emotion. In Y.L. Hanin (Ed.), Emotions in sport pp. 39-63). Champaign, IL: Human Kinetics.

Lazarus, R.S., \& Folkman, S. (1984). Stress, appraisal, and coping. New York: Springer Publishing.

Leprince, C., d'Arripe-Longueville, F., \& Doron, J. (2018). Coping in teams: Exploring athletes' communal coping strategies to deal with shared stressors. Frontiers in Psychology, 9, 1-11. doi: 10.3389/fpsyg.2018.01908.

Lyons, R.F., Mickelson, K.D., Sullivan, M.J.L., \& Coyne, J.C. (1998). Coping as a communal process. Journal of Social and Personal Relationships, 15, 579-605. doi: 10.1177/ 0265407598155001.

Morgan, P.B.C., Fletcher, D., \& Sarkar, M. (2013). Defining and characterizing team resilience in elite sport. Psychology of Sport and Exercise, 14, 549-559. doi: 10.1016/j.psy chsport.2013.01.004.

Morgan, P.B.C., Fletcher, D., \& Sarkar, M. (2015). Understanding team resilience in the world's best athletes: A case study of a rugby union World Cup winning team. Psychology of Sport and Exercise, 16, 91-100. doi: 10.1016/j.psy chsport.2014.08.007.

Morgan, P.B.C., Fletcher, D., \& Sarkar, M. (2017). Recent developments in team resilience research in elite sport. Current Opinion in Psychology, 16, 159-164. doi: 10.1016/j. copsyc.2017.05.013.

Murray, M.A., Joyner, A.B., Burke, K.L., Wilson, M.J., \& Zwald, A.D. (2005). The relationship between prayer and team cohesion in collegiate softball teams. Journal of Psychology \& Christianity, 24, 233-239.

National College Athletics Association (NCAA). (2007). Building new traditions: Hazing prevention in college athletics. Retrieved from https://www.ncaa.org/sites/default/files/ hazing\%20prevention\%20handbook\%2057315.pdf.

Neely, K.C., McHugh, T.F., Dunn, J.G.H., \& Holt, N.L. (2017). Athletes and parents coping with deselection in competitive youth sport: A communal coping perspective. Psychology of Sport and Exercise, 30, 1-9. doi: 10.1016/j. psychsport.2017.01.004.

Neil, G. (1980). The place of superstition in sport: The selffulfilling prophecy. Coaching Review, 3, 40-42.

Páez, D., Basabe, N., Ubillos, S., \& González-Castro, J.L. (2007). Social sharing, participation in demonstration, emotional climate, and coping with collective violence after the March 11th Madrid Bombings. Journal of Social Issues, 63, 323-337. doi: 10.1111/j.1540-4560.2007.00511.x.

Rappaport, R.A. (1971). Rituals, sanctity, and cybernetics. American Anthropologist, 73, 59-76.

Rees, T., \& Freeman, P. (2007). The effects of perceived and received support on self-confidence. Journal of Sports Sciences, 25, 1057-1065. doi: 10.1080/02640410600982279.

Reynolds, K.J. (2017). Self-categorization theory. The WileyBlackwell Encyclopedia of Social Theory. doi: 10.1002/ 9781118430873.est0327. 
Rossano, M. (2012). The essential role of ritual in the transmission and reinforcement of social norms. Psychological Bulletin, 138, 529-549. doi: 10.1037/a0027038.

Ruffle, B.J., \& Sosis, R. (2007). Does it pray to pay? Costly ritual and cooperation. The B.E. Journal of Economic Analysis and Policy, 7, 1-35. doi: 10.2202/1935-1682.1629.

Sarkar, M., \& Fletcher, D. (2014). Psychological resilience in sport performers: A review of stressors and protective factors. Journal of Sports Sciences, 32, 1419-1434. doi: 10.1080/ 02640414.2014 .901551$.

Sosis, R., \& Ruffle, B.J. (2003). Religious ritual and cooperation: Testing for a relationship on Israeli religious and secular Kibbutzim. Cultural Anthropology, 44, 713-722.

Stevens, R., Galloway, T., Lamb, J., Steed, R., \& Lamb, C. (2015). Team resilience: A neurodynamic perspective. In D.D. Schmorrow, \& C.M. Fidopiastis (Eds.), Foundations of Augmented Cognition (pp. 336-347). Berlin, Germany: Springer.

Stirling, A.E. (2009). Definitions and constituents of maltreatment in sport: Establishing a conceptual framework for research practitioners. British Journal of Sports Medicine, 43, 1091-1099. doi: 10.1136/bjsm.2008.051433.

Stirling, A.E., Bridges, E.J., Cruz, E.L., \& Mountjoy, M.L. (2011). Canadian Academy of Sport and Exercise Medicine position paper: Abuse, harassment, and bullying in sport. Clinical Journal of Sport Medicine, 21, 385-391. doi: 10.1097/ JSM.0b013e31820f9248.

Sullivan, P., \& Rickers, K. (2012). The effect of behavioral synchrony in groups of teammates and strangers. International Journal of Sport and Exercise Psychology, 11, 286-291. doi: 10.1080/1612197X.2013.750139.

Swann, W.B., Jr., Gómez, Á., Seyle, D.C., Morales, J.F., \& Huici, C. (2009). Identity fusion: The interplay of personal and social identities in extreme group behavior. Journal of Personality and Social Psychology, 96, 995-1011. doi: $10.1037 / \mathrm{a} 0013668$.

Swann, W.B., Jr., Jetten, J., Gómez, Á., Whitehouse, H., \& Bastian, B. (2012). When group membership gets personal: A theory of identity fusion. Psychological Review, 119, 441-456. doi: $10.1037 / \mathrm{a} 0028589$.

Tamminen, K.A., \& Crocker, P.R.E. (2013). "I control my own emotions for the sake of the team": Emotional self-regulation and interpersonal emotion regulation among female highperformance curlers. Psychology of Sport and Exercise, 14, 737-747. doi: 10.1016/j.psychsport.2013.05.002.

Tamminen, K.A., \& Gaudreau, P. (2014). Coping, social support, and emotion regulation in teams. In M. Beauchamp, \& M. Eys (Eds.), Group dynamics in exercise and sport psychology: Contemporary themes (2nd ed., pp. 222-239). New York: Routledge.
Tarr, B., Launay, J., Cohen, E., \& Dunbar, R.I.M. (2015). Synchrony and exertion during dance independently raise pain threshold and encourage social bonding. Biology Letters, 11, 1-4. doi: 10.1098/rsbl.2015.0767.

Tullett, A.M., Kay, A.C., \& Inzlicht, M. (2015). Randomness increases self-reported anxiety and neurophysiological correlates of performance monitoring. Social Cognitive and Affective Neuroscience, 10, 628-635. doi: 10.1093/scan/ nsu097.

Turchin, P., Whitehouse, H., Francois, P., Slingerland, E., \& Collard, M. (2012). A historical database of sociocultural evolution. Cliodynamics, 3, 271-293.

Turner, J.C., Hogg, M.A., Oakes, P.J., Reicher, S.D., \& Wetherell, M.S. (1987). Rediscovering the Social Group: A Self-Categorization Theory. Oxford: Blackwell.

Van Gennep, A. (1960). Rites of passage (M.B. Vizedom \& G.L. Caffee, Trans.). Chicago, IL: University of Chicago Press. (Original work published 1909).

Watson-Jones, R.E., \& Legare, C.H. (2016). The social function of group rituals. Current Directions in Psychological Science, 21, 42-46. doi: 10.1177/0963721415618486.

Weinstein, D., Launay, J., Pearce, E., Dunbar, R.I.M., \& Stewart, L. (2016). Group music performance causes elevated pain thresholds and social bonding in small and large groups of singers. Evolution and Human Behavior, 37, 152-158. doi: 10.1016/j.evolhumbe hav.2015.10.002.

Wen, N.J., Herrmann, P.A., \& Legare, C.H. (2016). Ritual increases children's affiliation with in-group members. Evolution and Human Behavior, 37, 54-60. doi: 10.1016/j. evolhumbehav.2015.08.002.

Whitehouse, H. (2004). Modes of religiosity: A cognitive theory of religious transmission. Walnut Creek, CA: AltaMira Press.

Whitehouse, H., \& Lanman, J.A. (2014). The ties that bind us: Ritual, fusion, and identification. Current Anthropology, 56, 674-695. doi: 10.1086/678698.

Witvrouw, E., Mahieu, N., Danneels, L., \& McNair, P. (2004). Stretching and injury prevention: An obscure relationship. Sports Medicine, 34, 443-449. doi: 10.2165/00007256200434070-00003.

Xygalatas, D., Mitkidis, P., Fischer, R., Reddish, P., Skewes, J., Geertz, A.W., Roepstorff, A., \& Bulbulia, J. (2013). Extreme rituals promote prosociality. Psychological Science, 24, 1602-1605. doi: 10.1177/0956797612472910.

Yamada, K., Kawata, Y., Kamimura, A., \& Hirosawa, M. (2017). The effect of unity in sport teams on athletes' mental health: Investigating the mediating role of resilience. International Journal of Sport and Health Science, 15, 55-64. doi: 10.5432/ ijshs.201509.

Cite this article as: Bonk D, Leprince C, Tamminen KA, \& Doron J (2019) Collective rituals in team sports: implications for team resilience and communal coping. Mov Sport Sci/Sci Mot, 105, 27-36 